\title{
Mood changes after delivery: role of the serotonin transporter gene
}

J. Sanjuan, R. Martin-Santos, L. Garcia-Esteve, J. M. Carot, R. Guillamat, A. Gutierrez-Zotes,

I. Gornemann, F. Canellas, E. Baca-Garcia, M. Jover, R. Navines, V. Valles, E. Vilella, Y. de Diego,

J. A. Castro, J. L. Ivorra, E. Gelabert, M. Guitart, A. Labad, F. Mayoral, M. Roca, M. Gratacos,

J. Costas, J. van Os and R. de Frutos

\section{Background}

Polymorphic variations in the serotonin transporter gene (5-HTT) moderate the depressogenic effects of tryptophan depletion. After childbirth there is a sharp reduction in brain tryptophan availability, thus polymorphic variations in $5-H T T$ may play a similar role in the post-partum period.

\section{Aims}

To study the role of 5-HTT polymorphic variations in mood changes after delivery.

\section{Method}

One thousand, eight hundred and four depression-free Spanish women were studied post-partum. We evaluated depressive symptoms at 2-3 days, 8 weeks and 32 weeks post-partum. We used diagnostic interview to confirm major depression for all probable cases. Based on two polymorphisms of 5-HTT (5-HTTLPR and STin2 VNTR), three genotype combinations were created to reflect different levels of 5-HTT expression.

\section{Results}

One hundred and seventy-three women (12.7\%) experienced major depression during the 32-week post-partum period. Depressive symptoms were associated with the highexpression 5-HTT genotypes in a dose-response fashion at 8 weeks post-partum, but not at 32 weeks.

\section{Conclusions}

High-expression 5-HTT genotypes may render women more vulnerable to depressive symptoms after childbirth.

\section{Declaration of Interest}

None. Funding detailed in Acknowledgements.
The most likely time for a woman to become depressed is after childbirth. ${ }^{1}$ Post-partum depression affects approximately $13 \%$ of women. ${ }^{2,3}$ Post-partum depression has a great impact on the family and economy, and is considered a major public health problem. ${ }^{4,5}$ There is general agreement that the dramatic physiological changes that occur post-partum increase a woman's vulnerability to depressive symptoms, including post-partum depression. ${ }^{6,7}$

Pregnancy and delivery are accompanied by hormonal changes as well as lower plasma tryptophan levels, both of which are thought to be aetiologically relevant to the mood changes that follow childbirth. ${ }^{6,8,9}$ Although plasma tryptophan availability is not directly related to mood changes, ${ }^{8}$ the brain tryptophan availability index is decreased after delivery and is related to depressive symptoms. ${ }^{10}$ The mood-lowering effects of experimental tryptophan depletion are controversial, ${ }^{11}$ perhaps because of differences in 5-HTT genotype-tryptophan interaction. In women with previous depressive episodes, 5-HTT genotype may moderate the risk for depressive symptoms after tryptophan depletion. ${ }^{12,13}$ If childbirth is considered an environmental factor, there may be a strong pathophysiological link between postpartum mood changes and the genes that moderate 5-hydroxytryptamine (5-HT) signalling.

Jans et $a l^{14}$ have proposed the concept of 'serotonergic vulnerability'. Disruption of the serotonergic system may occur at several levels, including tryptophan availability, 5-HT synthesis, release, reuptake or metabolism, and/or pre- or post-synaptic 5-HT receptors. 5-HTT has received special attention because it plays a crucial role in the regulation of serotonergic function. ${ }^{15,16}$

In the light of these findings, we designed a prospective longitudinal multicentre study to evaluate interactions between 5-HTT genotype and post-partum mood changes. We hypothesised that 5-HTT genotype would shape the risk for depressive symptoms in post-partum women. We considered three genotype combinations of 5-HTTLPR and Stin2 VNTR polymorphisms that predict differential 5-HTT expression. ${ }^{17}$ Given that the acute decline in tryptophan availability that follows childbirth resembles experimental tryptophan depletion, we hypothesised that highexpression 5-HTT genotypes would be associated with depressive symptoms in the weeks following childbirth.

\section{Method}

\section{Participants}

Between December 2003 and October 2004 women (2-3 days post-partum) were recruited in seven acute care teaching hospitals in Spain and invited to participate in a 32-week follow-up study. All participants were Spanish, not under psychiatric care during pregnancy, and able to understand and answer the clinical questionnaire. Women whose children died after birth were excluded. This study was approved by the institutional review boards of the participating hospitals. All women gave written informed consent.

\section{Measures}

All participants completed a semi-structured interview that included socio-demographic data: age, education level, marital status, number of children and employment status during pregnancy. Personal and family history of psychiatric illness was also recorded.

\section{Depression}

Depressive symptoms were assessed using the total score of the Edinburgh Postnatal Depression Scale (EPDS) ${ }^{18}$ with a Spanish validated version. ${ }^{19}$ The EPDS $^{18}$ is a 10 -item self-report scale with 
four possible responses and a total score from 0 to 30. The EPDS was administered at baseline (2-3 days post-partum), 8 weeks and 32 weeks post-partum. All women who scored $9 / 10$ in the EPDS were defined as probable cases of major depression. The cut-off of $9 / 10$ for major depression maximises the sensitivity to $100 \%$ and reaches a specificity of $89 \% .{ }^{19}$ All probable cases of major depression were evaluated using the Spanish version of the Diagnostic Interview for Genetics Studies (DIGS) ${ }^{20,21}$ adapted for post-partum depression. All interviews were conducted by clinical psychologists who were previously trained in DIGS using the same video case records. A high level of reliability (kappa $>0.8$ ) was obtained among interviewers.

\section{Genotyping}

The Puregene DNA purification kit (Gentra Systems) was used to extract genomic DNA from peripheral blood samples. Two polymorphisms of 5-HTT were analysed, both of which affect 5-HTT expression: 5-HTTLPR, a 44-base pair insertion/ deletion in the promoter region, and STin2, a multi-allelic 17-base pair variable number of tandem repeats (VNTR) within intron 2. Alleles of the 5-HTTLPR polymorphism were termed $S$ (short allele with the deletion) and $L$ (long allele with the insertion); the $L$ allele shows higher basal transcription than the $S$ allele. ${ }^{22}$ Two main alleles of the STin2 VNTR polymorphism have been described: STin2.10 and STin2.12, with 10 or 12 repeats respectively. STin2.12 displays higher transcriptional activity than STin2.10. ${ }^{23,24}$ STin2 alleles with seven and nine repeats occur at very low frequencies, and thus they were eliminated from the statistical analysis. Linked to 5-HTTLPR deletion insertion of a single nucleotide polymorphism (A/G) has been described. ${ }^{25}$ This single nucleotide polymorphism somehow modulates the functional effect on 5-HTTLPR promoter polymorphisms on gene expression. However, the Stin2 VNTR polymorphism acts as an enhancer having a dramatic effect on gene expression. Moreover, it has been experimentally showed that the combination of both polymorphisms (5-HTTLPR and Stin2 VNTR) strongly affect the transcriptional level of the $5-H T T$ gene. ${ }^{17}$ So, it seems more relevant to take into consideration the effect of both polymorphisms as a whole.

Taking into account the combined effect of both polymorphisms, significant differences in expression levels could be established based on high expression at one, both or neither of the loci. ${ }^{17}$ Three types of 5-HTT expression genotype combinations were used for the statistical analysis: no low-expressing genotype at either of the loci (LL/12.12); low-expressing genotype at one of the loci (LL/12.10, LL/10.10, LS/12.12, SS/12.12); and low-expressing genotypes at both loci (LS/12.10, LS/10.10, SS/ 12.10, SS/10.10).

\section{Statistical methods}

Outcomes were the EPDS score and major depression diagnosis at 8 weeks and 32 weeks post-partum. The independent variable was the expression level genotype.

Multiple regression analysis was used to determine whether expression level genotype was associated with EPDS scores. The linear trends were assessed in relation to the degree of genotype loading. The regression model of EPDS score at 8 weeks was corrected using the EPDS score at baseline, and the regression model of EPDS score at 32 weeks was corrected with the EPDS score at 8 weeks. The chi-squared test was used to estimate the significance of association between expression level genotype and major depression at 8 and 32 weeks post-partum. A likelihood ratio test for interaction was used to test whether the association between expression level genotype and depression at 8 weeks differed from expression level genotype at 32 weeks. Given the low power of these tests, a $P$-value of 0.1 was considered suggestive of differences in effect size at 8 and 32 weeks. STATA version 9.2 was used for the statistical analyses. Two-sided statistical significance was set at $P<0.05$.

\section{Results}

\section{Participants}

There were 1974 women who fitted the inclusion criteria for the study, $94(5 \%)$ women refused to participate and $76(3.8 \%)$ women were excluded because their EPDS questionnaires were incomplete. Thus, the final sample comprised 1804 women. At the 8-week follow-up, 1407 (78\%) women remained in the study. At 32 weeks, 1337 (74.1\%) women were evaluated (Fig. 1). Those women who dropped out during the follow-up period were compared with the final sample, revealing that women from lower social classes were the most likely to drop out $(P=0.005)$. The mean age of the participants was 31.7 years $($ s.d.=4.6), range $18-46$. Of the participants, $32 \%$ had attended primary school, $41 \%$ finished secondary school and $27 \%$ had a college degree. Most participants (68\%) were employed, 9\% were homemakers or students, $12 \%$ were unemployed and $11 \%$ were on sick leave or maternity leave. Forty-six per cent of the women were primiparous. Thirty-one per cent of the total sample has a family history of previous psychiatric treatment. Sixteen per cent had a previous personal history of psychiatric treatment.

\section{Clinical variables}

Of the 1407 women studied at 8 weeks post-partum, 214 scored 9/10 on the EPDS scale. A diagnosis of major depression was confirmed by DIGS in 112 (7.9\%) women. At 32 weeks post-partum, 323 of 1337 women scored $9 / 10$ on the EPDS, but only $61(4.5 \%)$ new cases of major depression were confirmed by DIGS. Overall, 173 women $(12.7 \%)$ had a major depression episode during the first 32 post-partum weeks (Fig. 1). There were no differences in socio-demographic variables (i.e. age, educational level, employment) between women diagnosed with major depression at 8 weeks post-partum and women diagnosed at 32 weeks post-partum.

Edinburgh Postnatal Depression Scale scores declined over the post-partum period. The mean EPDS score was 6.1 (s.d.=4.5) at baseline, $5.3($ s.d.=4.6) at 8 weeks post-partum and 4.4 (s.d.=4.7) at 32 weeks post-partum (Fig. 2).

\section{Frequency of polymorphisms}

Genotype analysis of 5-HTTLPR and Stin2 VNTR polymorphisms in the 1804 women revealed the following frequencies: $0.28 \mathrm{LL}$, $0.48 \mathrm{SL}$, and $0.24 \mathrm{SS}$ for 5-HTTLPR, and 0.46 STin2.12/STin2.12, 0.42 STin2.12/STin2.10, 0.10 STin2.10/STin2.10, 0.1 STin2.12/ STin2.9, and 0.1 STin2.10/STin2.9 for STin2 VNTR. Allele frequencies for the 5-HTTLPR polymorphism were 0.52 for L and 0.48 for S. For the STin2 VNTR polymorphism, STin2.12, STin2.10, and STin2.9 alleles occurred at a frequency of 0.67 , 0.32 and 0.01 respectively. Both polymorphisms were in HardyWeinberg equilibrium (5-HTTLPR $P=0.19$; STin2 VNTR $P=0.62$ ). No significant differences in the two polymorphisms were observed between samples from the seven different centres, and frequencies were similar to those reported for other Caucasian populations. ${ }^{26}$ The frequencies of the expression genotypes were: no low-expressing genotype at either of the loci $=0.088$; 


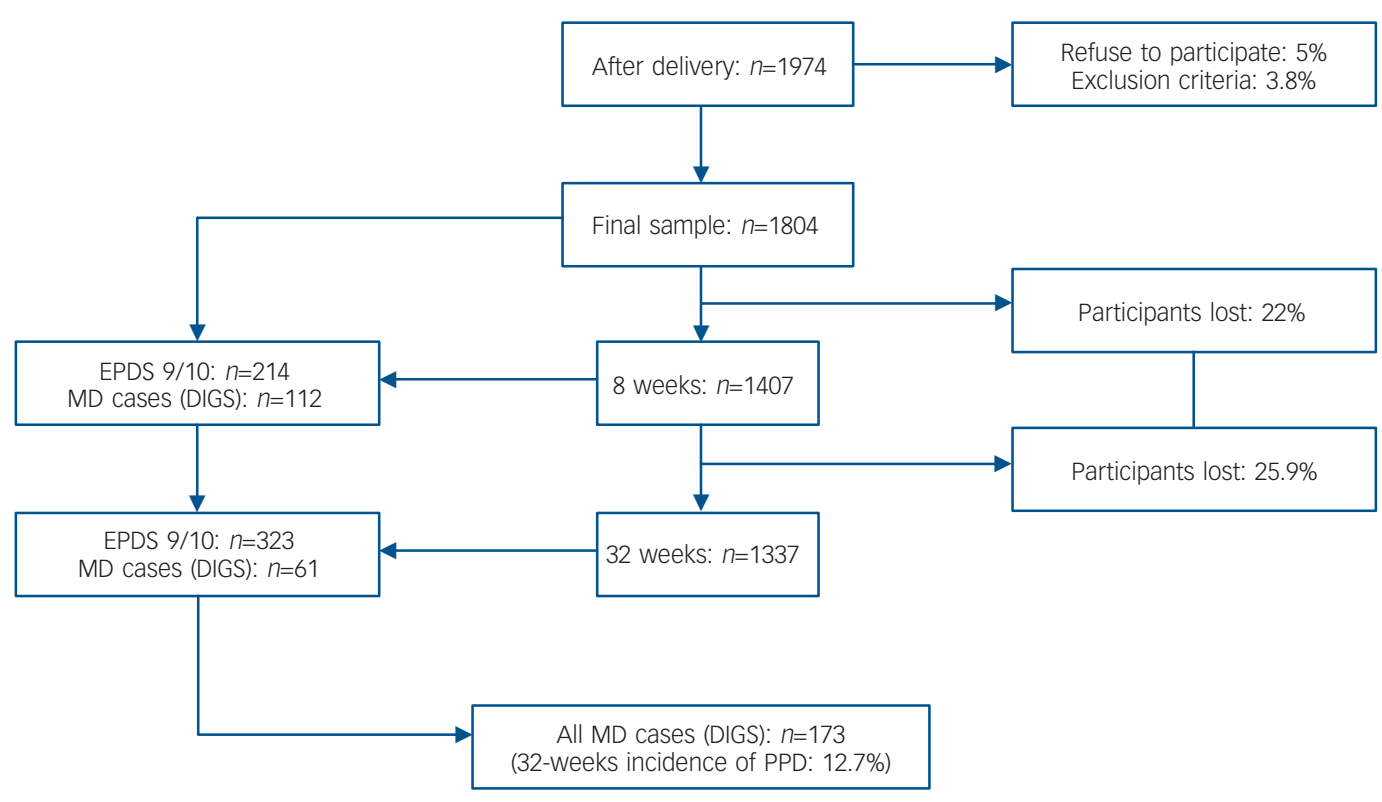

Fig. 1 Follow-up study of post-partum depression; EPDS, Edinburgh Postpartum Depression Scale; MD, major depression: DSM-IV major depression episode; DIGS, Diagnostic Interview for Genetics Studies; PPD, post-partum depression.

low-expressing genotype at one of the loci=0.572; and lowexpressing genotypes at both loci $=0.34$.

\section{Genotype frequencies according to serotonin transporter expression}

No significant difference in the distribution of major depression according to genotype combination was observed at 8 weeks $(P=0.089)$ or 32 weeks $(P=0.125)$ post-partum.

At baseline, genotype was not a predicator of EPDS score. At 8 weeks after childbirth, EPDS scores were related to 5-HTT expression levels in a dose-response fashion (regression coefficient $B=0.45,95 \%$ CI 0.09 to $0.82, P=0.015$ ). At 32 weeks post-partum, EPDS was not related to genotype $(B=-0.14,95 \% \mathrm{CI}-0.53$ to 0.26, $P=0.49$ ) (Table 1, Fig. 2). The test for interaction between time and expression level genotype suggested the difference between 8 and 32 weeks was not due to chance $\left(\chi^{2}=2.7\right.$, d.f. $=1$, $P=0.1$ ).

The differences remains significant after correcting for multiple comparison using Bonferroni correction between high expression (no low-expressing genotype at either of the loci) and low expression groups (low-expressing genotypes at both loci and low-expressing genotype at one of the loci) $(P=0.045)$. We also introduce age in our linear regression model with not significant effect on the results $(P=0.069)$.

\section{Discussion}

The incidence of post-partum depression in this study (12.7\%) is in concordance with previous reports. ${ }^{2,3}$ Although there was a trend $(P=0.089)$, no significant interaction between the expression level genotype and major depression was found. The EPDS score at 8 weeks post-partum was associated with the high-expression genotype. These results are in agreement with our hypothesis that 5-HTT genotype may modulate the mood changes, mainly depressive symptoms, that women experience just after delivery.
A number of factors may explain why the 5-HTT genotype was significantly associated with the EPDS score at 8 weeks, but not with major depression. First, it could be that the lack of significance $(P=0.089)$ may be a statistical problem related to the relatively small sample size of women with major depression $(n=173)$ and/or a weak effect of the 5-HTT genotype. Highexpression 5-HTT polymorphisms may promote tryptophan depletion and induce major depression post-partum, but only when other genetic and/or environmental factors are present (e.g. lack of social support or life events). It seems unlikely that EPDS score at 8 weeks may reflect the 'blues', a transient emotional liability that affects about $50 \%$ of post-partum women. ${ }^{27}$ The 'blues' are quantitatively and qualitatively different from depression $;^{28}$ they emerge during the first post-partum week and disappear by the second week. Moreover, there is some evidence that the DSM-IV ${ }^{29}$ or ICD- $10^{30}$ definition of major

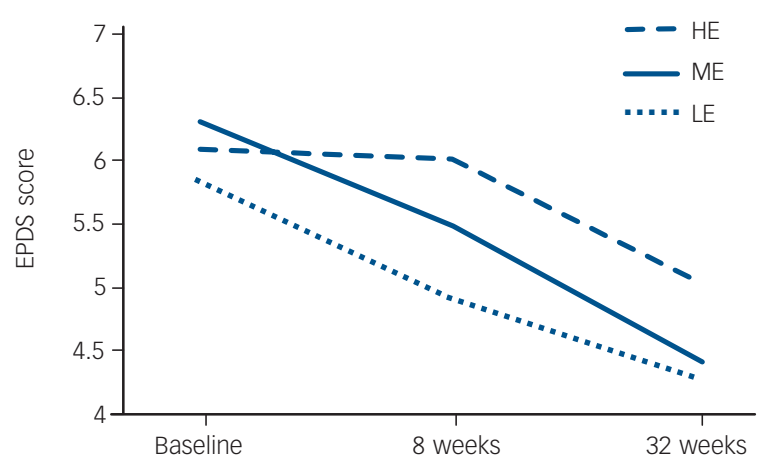

Fig. 2 Edinburgh Postnatal Depression Scale (EPDS) score over time (2-3 days, 8 weeks and 32 -weeks post-partum) in relation to the different $5-H T T$ genotype combinations. $\mathrm{HE}$, no low-expressing genotype at either of the loci; ME, lowexpressing genotype at one of the loci; LE, low-expressing genotypes at both loci. 
Table 1 Frequency of different 5-HTT genotype combinations (5-HTT-GC) and Edinburgh Postnatal Depression Scale (EPDS) score at baseline (2-3 days post-partum), 8 weeks post-partum, and 32 weeks post-partum

\begin{tabular}{|c|c|c|c|c|c|c|c|c|c|}
\hline \multirow[b]{2}{*}{$\begin{array}{l}\text { Expression level } \\
\text { genotypes }\end{array}$} & \multicolumn{3}{|c|}{ Baseline } & \multicolumn{3}{|c|}{8 weeks } & \multicolumn{3}{|c|}{32 weeks } \\
\hline & Mean & $\begin{array}{l}\text { Regression coefficient } \\
\qquad(95 \% \mathrm{Cl})\end{array}$ & $P$ & Mean & $\begin{array}{l}\text { Regression coefficient } \\
\qquad(95 \% \mathrm{Cl})\end{array}$ & $P$ & Mean & $\begin{array}{l}\text { Regression coefficient } \\
\qquad(95 \% \mathrm{Cl})\end{array}$ & $P$ \\
\hline LE & 5.85 & $0^{\mathrm{a}}$ & & 4.89 & $0^{\mathrm{a}}$ & & 4.31 & $0^{\mathrm{a}}$ & \\
\hline ME & 6.29 & $0.44(-0.00$ to 0.88$)$ & 0.052 & 5.49 & $0.37(-0.10$ to 0.84$)$ & 0.13 & 4.40 & $-0.28(-0.79$ to 0.23$)$ & 0.28 \\
\hline $\mathrm{HE}$ & 6.08 & $0.23(-0.54$ to 1.00$)$ & 0.56 & 6.00 & 1.02 (0.18 to 1.88$)$ & 0.018 & 5.03 & $-0.08(-0.98$ to 0.83$)$ & 0.87 \\
\hline $\begin{array}{l}\text { Regression coefficient } \\
\text { linear trend }{ }^{b}\end{array}$ & & $0.24(-0.10$ to 0.58$)$ & 0.16 & & 0.45 (0.09 to 0.82) & 0.015 & & $-0.14(-0.53$ to 0.26$)$ & 0.49 \\
\hline
\end{tabular}

depression is an arbitrary diagnostic convention imposed upon a continuum of depressive symptoms. ${ }^{31-33}$

Reduced availability of brain tryptophan during the postpartum period may explain the high $(>9)$ EPDS scores. Experimental tryptophan depletion frequently leads to transient symptoms of depression in vulnerable individuals. ${ }^{11}$ The brain tryptophan availability index decreases by $15 \%$ after delivery and is associated with depressive symptoms. ${ }^{10}$ This reduction in the early post-partum period is not associated with plasma tryptophan levels ${ }^{8}$ but rather with a dramatic increase in circulating levels of free amino acids that compete with tryptophan, such as leucine, isoleucine, valine and tyrosine, resulting in a significantly impaired transport of tryptophan across the blood barrier. The brain tryptophan availability index is calculated according to the Michaelis model for substrate competition on enzymes or transporters taking into account the total plasma tryptophan concentration and the blood concentration of competitor amino acids. So, the post-partum period is a 'natural model' of tryptophan depletion, and individuals with the LL 5-HTTLPR genotype indeed present with more depressive symptoms after tryptophan depletion. In a study of 43 individuals currently in remission from major depression, those with the LL genotype had significantly higher scores on the Hamilton Rating Scale for Depression (HRSD) than LS or SS carriers. ${ }^{12}$ Moreno et al suggested that rapid uptake of 5-HT in people with LL, combined with decreased brain $5-\mathrm{HT}$ availability during tryptophan depletion, produces a substantial decrease in serotonergic transmission, thereby enhancing depressive symptoms. ${ }^{12}$ A recent study ${ }^{13}$ confirms that people with previous depressive episodes and the LL genotype have the greatest increase in HRDS scores after tryptophan depletion. The gene-tryptophan interaction is further supported by a double-blind placebo study of 15 healthy SS and 15 healthy LL volunteers. The SS genotype group outperformed the LL genotype group in tests of episodic memory and attention. ${ }^{34}$ Thus, it may be hypothesised that women with high-expression 5-HTT genotypes have an increased risk of depressive symptoms post-partum because serotonergic transmission is reduced. In line with the above observation, the genotype effect disappears by 32 weeks post-partum.

The decline of EPDS scores over the post-partum period is also consistent with previous observations. ${ }^{35,36}$ Depressive symptoms in women with a high-expression 5-HTT genotype show the least change over time, possibly reflecting differences in the rate of brain tryptophan availability index normalisation during the post-partum period. Other aetiological mechanisms of post-partum depression, such as familiality, are in agreement with the time of onset observed in our study. ${ }^{37}$ In tryptophan depletion studies, high-expression 5-HTT genotypes are at risk, whereas low-expression variants have been implicated in life event interactions. ${ }^{38-44}$ This suggests that gene effects on acute tryptophan depletion and stress response are distinct. According to the 'serotonergic vulnerability' model, ${ }^{14}$ mood changes after delivery are the result of complex interactions between multiple variables, including acute hormonal changes and tryptophan depletion, which is mediated by 5-HTT genotype. In support of this hypothesis the risks of post-partum depression have been associated with a tryptophan hydroxylase gene polymorphism. ${ }^{45}$

To the best of our knowledge, there are two studies of 5-HTT expression during pregnancy and delivery. Coyle et al ${ }^{48}$ found a significant $(P<0.003)$ over-representation of STin 2.12 allele (the high expression allele) in 127 women with bipolar disorder, who later developed puerperal psychosis within a few days of delivery, compared with 380 controls. Scheid et al ${ }^{47}$ performed a cross-sectional study of 568 pregnant women to examine possible interactions between 5-HTTLPR polymorphisms and different types of life stressors relative to depressive symptoms. The only significant interaction identified was the sub-construct of 'childhood abuse'. Their study, however, was conducted during pregnancy, not during the post-partum period, and therefore it is unlikely it tapped into specific mechanisms associated with tryptophan depletion.

The present study has several limitations. First, the brain tryptophan availability index was not measured. Second, the results pertain to White Spanish women and may or may not be applicable to other ethnic groups. Lastly, it is impossible to exclude the possibility that depressive symptoms account for the $27 \%$ attrition rate at 32 week post-partum. However, it is unlikely that genotype has a differential effect on attrition, making this an unlikely cause of bias. It is also worth mentioning several strengths of our study. First, our sample is relatively large. Second, the study was longitudinal and depression was evaluated categorically and dimensionally to increase sensitivity of the measure. Third, we analysed the combination of two (5-HTTLPR and Stin2 VNTR) polymorphisms related to functional expression. Finally, the homogeneity of our sample may be one of the principal methodological strengths. All participants were White Spanish women, all were young and, perhaps most importantly, all were evaluated during the very well-defined post-partum risk period.

In summary, our results suggest that there are no 'bad' or 'good' 5-HTT genotypes in relation to depression. Highexpression 5-HTT genotypes might be a risk factor under certain environmental conditions such as tryptophan depletion after childbirth. This study supports a new hypothesis for understanding the biological mechanisms underlying depressive symptoms after delivery and encourages further study of gene-tryptophan interactions in mood disorders. 
J. Sanjuan, MD, PhD, Hospital Clínico, UV, CIBER Enfermedades Mentales (CIBERSAM), Valencia, Spain; R. Martin-Santos, MD, PhD, L. Garcia-Esteve, MD PhD, IMIM-Hospital del Mar and Hospital Clínico, Barcelona, Spain; J. M. Carot, PhD PhD, Departamento de Estadística e Investigación Operativa, UPV, Valencia, Spain; R. Guillamat, MD, PhD, Corporación Sanitaria Parc Tauli, Sabadell, Spain;

A. Gutierrez-Zotes, PhD, Hospital Psiquiátrico, Instituto Pere Mata, URV Reus, Spain I. Gornemann, MD, PhD, Fundación IMABIS, Hospital Carlos Haya, Málaga, Spain; F. Canellas, MD, PhD, Hospital Son Dureta (IUNICS), Palma de Mallorca, Spain; E. Baca-Garcia, MD, PhD, Fundación Jiménez Díaz, UAM, CIBERSAM, Madrid, Spain M. Jover, Hospital Clínico, UV, CIBERSAM,Valencia, Spain; R. Navines, MD, PhD, IMIM-Hospital del Mar and Hospital Clínico, Barcelona, Spain; V. Valles, Corporación Sanitaria Parc Tauli, Sabadell, Spain; E. Vilella, PhD, Hospital Psiquiátrico, Instituto Pere Mata, URV Reus, Spain; Y. de Diego, PhD, Fundación IMABIS, Hospital Carlos Haya, Málaga, Spain; J. A. Castro, PhD, Hospital Son Dureta (IUNICS), Palma de Mallorca, Spain; J. L. Ivorra, Hospital Clínico, UV, CIBERSAM, Valencia, Spain; E. Gelabert, IMIM-Hospital del Mar and Hospital Clínico, Barcelona, Spain; M. Guitart, MD, PhD, Corporación Sanitaria Parc Tauli, Sabadell, Spain; A. Labad MD, PhD, Hospital Psiquiátrico, Instituto Pere Mata, URV Reus, Spain; F. Mayoral, MD, PhD, Hospital Son Dureta (IUNICS), Palma de Mallorca, Spain; M. Roca, MD, PhD, Hospital Son Dureta (IUNICS), Palma de Mallorca, Spain; M. Gratacos, PhD, CIBER en Epidemiología y Salud Pública (CIBERESP) (CRG), Barcelona, Spain; J. Costas, PhD, SERGAS Hospital Clínico Universitario, Santiago de Compostela, Spain; J. van Os, MD $\mathrm{PhD}$, Department of Psychiatry and Neuropsychology, Maastricht University, Netherlands and Division of Psychological Medicine, Institute of Psychiatry, London, UK' R. de Frutos, PhD, Hospital Clínico, UV, CIBERSAM,Valencia, Spain.

Correspondence: Julio Sanjuán, Unidad de Psiquiatría, Facultad de Medicina Valencia, Universidad de Valencia, Blasco Ibáñez 15, 46010 Valencia, Spain. Email: julio.sanjuan@uv.es

First received 20 Sep 2007, final revision 2 May 2008, accepted 29 May 2008

\section{Acknowledgements}

This work was supported by the Instituto Carlos III (Spanish Ministry of Health) gran numbers: PI041635, PI041783, PI041779, PI041758, PI041761, PI041791, PI041766 and PI041782, as well as The Spanish Psychiatric Genetics and Genotyping network GO3/184 and the Spanish Mental Health Network: CIBER Enfermedades Mentales. We also thank M. Pulido for editing the manuscript.

\section{References}

1 Kendler KS, Neale MC, Kessler RC, Heath AC, Eaves L. A population-based study of major depression in women. The impact of varying definitions of illness. Arch Gen Psychiatry 1992; 49: 257-66.

2 O'Hara MW, Swain AM. Rates and risk of postnatal depression - a meta analysis. Int Rev Psychiatry 1996; 8: 37-54.

3 García-Esteve L, Ascaso C, Ojuel J, Navarro P. Validation of the Edinburgh Postnatal Depression Scale (EPDS) in Spanish mothers. J Affect Disord 2003; 75: 71-6.

4 Petrou S, Cooper P, Murray L, Davidson LL. Economic costs of post-natal depression in a high-risk British cohort. Br J Psychiatry 2002; 181: 505-12.

5 Wisner KL, Chambers C, Sit DK. Postpartum depression: a major public health problem. JAMA 2006; 296: 2616-8.

6 Bloch M, Daly RC, Rubinow DR. Endocrine factors in the etiology of postpartum depression. Compr Psychiatry 2003; 44: 234-46.

7 Serreti A, Olgiati P, Colombo C. Influence of postpartum onset on the course of mood disorders. BMC Psychiatry 2006; 6: 1-7

8 Maes M, Ombelet W, Verkerk R, Bosmans E, Scharpé S. Effects of pregnancy and delivery on the availability of plasma tryptophan to the brain: relationships to delivery-induced immune activation and early post-partum anxiety and depression. Psychol Med 2001; 31: 847-58.

9 Payne JL. The role of estrogen in mood disorders in women. Int Rev Psychiatry 2003; 15: 280-90.

10 Baïlara KM, Henry C, Lestage J, Launay JM, Parrot F, Swendsen J, Sutter AL, Roux D, Dallay D, Demotes-Mainard J. Decreased brain tryptophan availability as a partial determinant of post-partum blues. Psychoneuroendocrinology 2006; 31: 407-13.

11 Van der Does AJ. The mood-lowering effect of tryptophan depletion: possible explanation for discrepant findings. Arch Gen Psychiatry 2001; 58: 200-2.

12 Moreno FA, Rowe DC, Kaiser B, Chase D, Michaels T, Gelernter J, Delgado PL Association between a serotonin transporter promoter region polymorphism and mood response during tryptophan depletion. Mol Psychiatry 2002; 7 : 213-6.

13 Neumeister A, Hu XZ, Luckenbaugh DA, Sachwrz M, Nugent AC, Bonne O, Herscovitch P, Goldman D, Drevets WC, Charney DS. Differential effects of 5-HTTLPR genotypes on the behavioral and neural responses to tryptophan depletion in patients with major depression and controls. Arch Gen Psychiatry 2006; 63: 978-86.
14 Jans LA, Riedel WJ, Markus CR, Blokland A. Serotonergic vulnerability and depression: assumptions, experimental evidence and implications. $\mathrm{Mol}$ Psychiatry 2007; 12: 522-43.

15 Murphy DL, Li Q, Engel S, Wichems C, Andrews A, Lesch KP, Uhl G. Genetic perspectives on the serotonin transporter. Brain Res Bull 2001; 56: 487-94.

16 Lesch KP, Gutknecht L. Pharmacogenetics of the serotonin transporter. Biol Psychiatry 2005; 29: 1062-73.

17 Hranilovic D, Stefulj J, Schwab S, Borrmann-Hassenbach M, Albus M, Jernej B, Wildenauer D. Serotonin transporter promoter and intron 2 polymorphisms: relationship between allelic variants and gene expression. Biol Psychiatry 2004; 55: 1090-4.

18 Cox JL, Holden JM, Sagovsky R. Detection of postnatal depression. Development of the 10-item Edinburgh Postnatal Depression Scale. Br J Psychiatry 1987; 150: 782-6.

19 Navarro P, Ascaso C, García-Esteve L, Aguado J, Torres A, Martín-Santos R. Postnatal psychiatric morbidity: a validation study of the GHQ-12 and the EPDS as screening tools. Gen Hosp Psychiatry 2007; 29: 1-7.

20 Nurnberger Jl, Blehar MC, Kaufmann J. Diagnostic interview for genetic studies. Rationale, unique features, and training. NIMH Genetic Initiative. Arch Gen Psychiatry 1994; 51: 849-59.

21 Roca M, Martín-Santos R, Sainz J, Obiols J, Serrano MJ, Torrens M, Subirà S, Gili M, Navinés R, Ibañez A, Nadal M, Barrantes N, Cañellas F. Diagnostic Interview for Genetics Studies (DIGS): inter-rater and test-retest reliability and validity in a Spanish population. Eur Psychiatry 2007; 22: 44-8.

22 Heils A, Teufel A, Petri S, Stöber G, Riederer P, Bengel D, Lesch KP. Allelic variation of human serotonin transporter gene expression. J Neurochem 1996; 66: 2621-4.

23 Fiskerstrand CE, Lovejoy EA, Quinn JP. An intronic polymorphic domain often associated with susceptibility to affective disorders has allele dependent differential enhancer activity in embryonic stem cells. FEBS Letters 1999; 458: $171-4$.

24 Mackenzie A, Quinn J. A serotonin transporter gene intron 2 polymorphic region, correlated with affective disorders, has allele-dependent differential enhancer like properties in the mouse embryo. Proc Natl Acad Sci USA 1999; 96: 15251-5.

25 Nakamura M, Ueno S, Sano A, Tanabe $H$. The human serotonin transporter gene linked polymorphism (5-HTTLPR) shows ten novel allelic variants. $\mathrm{Mol}$ Psychiatry 2000; 5: 32-8.

26 Fan JB, Sklar P. Meta-analysis reveals association between serotonin transporter gene STin2 VNTR polymorphism and schizophrenia. $\mathrm{Mol}$ Psychiatry 2005; 10: 928-38.

27 Seyfried LS, Marcus SM. Postpartum mood disorders. Int Rev Psychiatry 2003; 15: 231-42.

28 Miller $\mathrm{L}$, Rukstalis M. Beyond the 'blues'. Hypotheses about postpartum reactivity. In Postpartum Mood Disorder (ed $\sqcup$ Miller): 3-19. American Psychiatric Press, 1999.

29 American Psychiatric Association. Diagnostic and Statistical Manual of Mental Disorder (4th edn) (DSM-IV). APA, 1994.

30 World Health Organization. The ICD-10 Classification of Mental and Behavioural Disorders. Diagnostic Criteria for Research. WHO, 1992.

31 Goldberg DP. A dimensional model for common mental disorders. Br J Psychiatry 1996; 168: 44-9.

32 Kendler KS, Gardner CO Jr. Boundaries of major depression: an evaluation of DSM-IV criteria. Am J Psychiatry 1998; 155: 172-7.

33 Aggen SH, Neale MC, Kendler KS. DSM criteria for major depression: evaluating symptom patterns using latent-trait item response models. Psychol Med 2005; 35: 475-87.

34 Roiser JP, Müller U, Clark L, Sahakian BJ. The effects of acute tryptophan depletion and serotonin transporter polymorphism on emotional processing in memory and attention. Int J Neuropsychopharmacol 2007; 10: 449-61.

35 Evans J, Heron J, Francomb H, Oke S, Golding J. Cohort study of depressed mood during pregnancy and after childbirth. BMJ 2001; 323: 257-60.

36 Dennis CL. Can we identify mothers at risk for postpartum depression in the immediate postpartum period using the Edinburgh Postnatal Depression Scale? J Affect Disord 2004; 78: 163-9.

37 Forty L, Jones L, Macgregor S, Caesar S, Cooper C, Hough A, Dean L, Dave S, Farmer A, McGuffin P, Brewster S, Craddock N, Jones I. Familiality of postpartum depression in unipolar disorder: results of a family study. Am J Psychiatry 2006; 163: 1549-53.

38 Caspi A, Sugden K, Moffitt TE, Taylor A, Craig IW, Harrington H, McClay J, Mill J, Martin J, Braithwaite A, Poulton R. Influence of life stress on depression: moderation by a polymorphism in the 5-HTT gene. Science 2003; 301: 386-9.

39 Kendler KS, Kuhn JW, Vittum J, Prescott CA, Riley B. The interaction of stressful life events and a serotonin transporter polymorphism in the 
prediction of episodes of major depression: a replication. Arch Gen Psychiatry 2005; 62: 529-35.

40 Kaufman J, Yang BZ, Douglas-Palumberi H. Social supports and serotonin transporter gene moderate depression in maltreated children. Proc Natl Acad Sci USA 2004; 101: 17316-21.

41 Jacobs N, Kenis G, Peeters, Derom C, Vlietinck R, van Os J. Stress-related negative affectivity and genetically altered serotonin transporter function: evidence of synergism in shaping risk of depression. Arch Gen Psychiatry 2006; 63: 989-96.

42 Zalsman G, Huang Y, Oquendo MA, Burke AK, Hu XZ, Brent DA, Ellis SP, Goldman D, Mann JJ. Association of a triallelic serotonin transporter gene promoter region (5-HTTLPR) polymorphism with stressful life events and severity of depression. Am J Psychiatry 2006; 163: 1588-93.

43 Wilhelm K, Mitchell PB, Niven H, Finch A, Wedgwood L, Scimone A, Blair IP, Parker G, Schofield PR. Life events, first depression onset and the serotonin transporter gene. Br J Psychiatry 2006; 188: 210-5.
44 Cervilla J, Molina E, Rivera M, Torres-González F, Bellón JA, Moreno $B$, Luna JD, Lorente JA, Mayoral F, King M, Nazareth I. The risk for depression conferred by stressful life events is modified by variations at the serotonin transporter 5HTTLPR genotype: evidence from the Spanish PREDICT Gene cohort. Mol Psychiatry 2007; 12: 748-55.

45 Sun HS, Tsai HW, Ko HC, Chang FM, Yeh TL. Association of tryptophan hydroxylase gene polymorphism with depression, anxiety and comorbid depression and anxiety in a population-based sample of postpartum Taiwanese women. Genes Brain Behav 2004; 3: 328-36.

46 Coyle N, Jones I, Robertson E, Lendon C, Craddock N. Variation at the serotonin transporter gene influences susceptibility to bipolar affective puerperal psychosis. Lancet 2000; 356: 1490-1.

47 Scheid JM, Holzman CB, Jones N, Friderici KH, Nummy KA, symonds LL, Sikorskii A, Regier MK, Fisher R. Depressive symptoms in mid-pregnancy, lifetime stressors and the 5-HTTLPR genotype. Genes Brain Behav 2007; 6: 453-64.

case report

\section{A case of male anorexia with Klinefelter's syndrome, 22 years later}

\section{Christopher Paul Szabo}

In 1986 the British Journal of Psychiatry published a report 'A case of anorexia nervosa with Klinefelter's syndrome' (Hindler CG, Norris, DL. Br J Psychiatry, 149: 659-660). The case was of interest as it was the first documented case of anorexia nervosa in a male associated with Klinefelter's syndrome. The patient had initially been diagnosed as having 'atypical anorexia nervosa' and the Klinefelter's syndrome was cytogenetically proven. No other associated organic pathology was diagnosed at that time. Specifically, computed tomography (CT) scans were reported within normal limits.

Clinically, the patient had presented (in 1985) with significant weight loss, from $50 \mathrm{~kg}$ to $39.9 \mathrm{~kg}$ over the preceding 2 years. He had a history of prior admission to the unit (7 years earlier, at the age of 13) with a diagnosis of anorexia nervosa. In addition to the weight loss, he reported vomiting five times per week in the 2 months before the admission, but not as a consequence of binge eating or guilt following perceived overeating. The vomiting was not self-induced. The patient denied any fear of fatness, reporting a loss of appetite, excessive fluid intake and persistently feeling cold (features not inconsistent with anorexia nervosa). His limb length, sexual characteristics and delayed puberty suggested he had Klinefelter's syndrome.

Following the admission in 1985, a magnetic resonance image (MRI) scan was undertaken due to the onset of an ataxic gait, tremor and noticeable nystagmus. A cerebellar tumour was diagnosed, identified as an 'atypical teratoma' during a subsequent neurosurgery. Because of local infiltration and incomplete tumour excision, a course of radiotherapy followed the surgery. Thereafter, the patient gained $5.5 \mathrm{~kg}$ over the first 3 months and a further $3.5 \mathrm{~kg}$ in the next 6 months to weigh $51 \mathrm{~kg}$. His recovery was generally satisfactory. However, in January 1988 his speech began to slur and he became uncoordinated. A CT scan revealed a tumour in the right frontal lobe. Following surgery (with adjuvant radiotherapy), a germinoma was diagnosed. Review of the pathology findings concluded that both tumours had indeed been germinomas.

Between 1988 and 2000 a number of MRI scans did not reveal any recurrent tumour growth. The patient's last gadolinium-enhanced MRI scan (2005) showed no evidence of tumour recurrence in either the right frontal lobe or posterior fossa, and generalised cerebral and cerebellar involutional changes, possibly secondary to previous radiotherapy. At the most recent consultation (2006), the patient reported no eatingrelated concerns and he had no symptoms of an eating disorder.

Given that both tumours (frontal and cerebellar) were diagnosed as germinomas, it may be that although the cerebellar tumour had been the one initially diagnosed, the one in the frontal lobe had been there all along. With hindsight it appears possible that the initial clinical features were more harbingers of the pathology that was ultimately diagnosed, rather than of an eating disorder. Features of a developing neurological disturbance were noted during the various admissions to the eating disorders unit. However, they were not as prominent as the weight loss and vomiting which, together with the diagnosis of Klinefelter's syndrome and the initial negative CT scans, may have deflected attention. The reported absence of the more complex features of psychopathology usually associated with an eating disorder further suggests a more likely primarily neurological pathology in evolution.

The case highlights a specific clinical issue - the clinical interpretation of disordered eating and the distinction of such behaviour from an eating disorder.

Christopher Paul Szabo, University of the Witwatersrand, Division of Psychiatry, Faculty of Health Sciences, 7 York Rd, Parktown 2193, Johannesburg, South Africa. Email: Christopher.szabo@wits.ac.za 